\title{
EDYTA MĄSIOR
}

\section{O ROLI ZNAGZENIU PRZYPADKU}

\author{
Balon w sztuce
}




\section{ABSTRAKT}

Artykuł przybliża poszukiwania oparte na tematyce sceny tenisowej przedstawionej za pomocą tekstu, filmu i technologii, równocześnie nakreślając rzeczywistość przybliżoną za pomocą różnych mediów. Kontekst badań odnosi się do przykładów zaczerpniętych z dzieł sztuki z lat 60. i 70. XX wieku, to jest z filmu Powiększenie (Blow-Up, 1966) w reżyserii Michelangelo Antonioniego, w którym autor sięga do motywów zaczerpniętych z poetyckiego dzieła Julio Cortázara Babie lato (Las babas del diablo, 1959) i meczu tenisowego, jak go przedstawia Robert Rauschenberg w realizacji Open Score (1966). Te dzieła sztuki łączy wyjątkowy świat. Interesująca jest dla mnie relacja medium-działanie-mechanizm rozgrywanej akcji, szczególnie w odniesieniu do technologii i nowych możliwości. Celem tych badań i analizy - wynikających z początkowej, pierwotnie empirycznej obserwacji jest utrwalenie i opisanie tożsamości (charakteru) tego, co jest obserwowane (przedmiotu), oraz obserwatora, jak również interakcja między tym, co obserwowane, a obserwatorem. Jak pokazać, że "grać granie” to część gry? Przyczynkiem do poszukiwania była własna praca artystyczna związana z przemysłowym przedmiotem, jakim jest balon, który został przeniesiony w obszar działania twórczego. Pierwsza część pracy teoretycznej dotyczy zagadnienia roli i znaczenia przypadku, druga balonu w sztuce. 


\section{StOWA KLUGZE}

Mecz tenisowy ; Balon ; Obserwator ; Media ; Technologie ; Interaktywność ; Doświadczenie ; Gra ; Film ; Interakcja ; Interaktor ; Język ; Kreatywność ; Metafora ; Obserwacja ; Odbiorca ; Obiekt ; Oddech ; Palimpsest ; Pantomima ; Powietrze ; Przestrzeń ; Przekształcanie ; Przypadek ; Rozgrywka ; Różnica ; Sygnał ; Symbol ; Sztuka ; Technologia ; Tekst ; Znak ; Diody LED ; Instalacja audiowizualna ; Żyłka ; Michelangelo Antonioni ; Guido Aristarco ; Arystoteles ; Roland Barthes ; Carlo di Carlo ; Julio Cortázar ; Nikos Daskalothanasis ; Jacques Derrida ; Thomas Stearns Eliot ; Heinz von Foerster ; Jean-Luc Godard ; Dionisis Kavathas ; Paul Klee ; Billy Klüver ; Giannis Kunellis ; Stéphane Mallarmé ; Rosa Martinez ; Umberto Maturana ; Marshall McLuhan ; Piet Mondrian ; Robert Motherwall ; Friedrich Nietzsche ; Nikos Navridis ; Pablo Picasso ; Robert Rauschenberg ; Ad Reinhard ; Olivier Sacks ; Ferdinand de Saussure ; Francisco Varela ; Paul Watzlawick ; Ludwik Wittgenstein 
TOM 1, NR 1 (2020)

Utwór udostępniany na licencji Creative Commons Uznanie autorstwa 4.0 Międzynarodowe.

Wydawca: Akademia Sztuk Pięknych im. Jana Matejki w Krakowie, Wydział Architektury Wnętrz Redakcja: prof. dr hab. Beata Gibała-Kapecka, mgr Marika Wato

Opracowanie graficzne: Marika Wato

Fotografia na stronie tytułowej: Edyta Mąsior / żródło: archiwum autora

Czasopismo "inAW Journal" powstało dzięki dofinansowaniu w ramach Projektu "Projektowanie Przyszłości - Program Rozwoju Akademii im. Jana Matejki w Krakowie na lata 2018 - 2022"

Fundusze Europejskie Wiedza Edukacja Rozwój
Rzeczpospolita Polska
Unia Europejska Europejski Fundusz Spoteczny

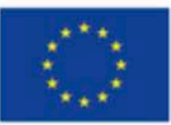




\section{dr hab. Edyta Mąsior}

Akademia Sztuk Pięknych im. Jana Matejki w Krakowie

\section{O roli i znaczeniu przypadku}

\section{Balon w sztuce}

Prolog 2

Geneza pracy artystycznej $\quad 5$

Od przedmiotu do języka

Działanie w dwóch odsłonach 18

Epilog 20

\section{Prolog}

Sztuka jest doświadczeniem, nie obiektem.

Robert Motherwell

Dzieło Michelangelo Antonioniego Powiększenie (Blow-up, 1966), a w szczególności scena gry mimów w tenisa, przywołała mi na myśl scenę rozgrywaną u Roberta Rauschenberga (Open Scorel, 1966). Mając możliwość porozmawiania z Carlem di Carlo² (Kraków, 2012), uświadomiłam sobie, że była to słuszna konkluzja. Carlo di Carlo potwierdził moje przypuszczenia i analizę. Podał kilka szczegółów na temat mało znanej współpracy Antonioniego i Rauschenberga przy realizacji scenografii, która ostatecznie nie doszła do skutku. Z relacji reżysera wynika, że ta współpraca miała

1 Tytuł happeningu Roberta Rauschenberga zawiera słowo score, które wyraża w tłumaczeniu na język polski zarówno „partyturę”, jak i „wynik”. Wobec powyższego tytuł działa może być tłumaczony jako „otwarta partytura" albo „otwarty wynik". Interesująco opisuje kwestię tytułu Antoni Michnik w artykule pt. Gem, set, algorytm. Intermedialne projekty wykorzystujące dane tenisowe, „Kultura Współczesna”, 2017, nr 1. Happening Open Score jako część projektu 9 wieczorów: teatr i inżynieria (9 Evenings: Theatre and Engineering) odbył się w Nowym Jorku w 1966 roku.

2 Rozmawiałam z reżyserem Carlem di Carlo 26 listopada 2012 roku w Krakowie. 
TOM 1, NR 1 (2020)

miejsce. To był ślad, który instynktownie znalazłam. Czy między tymi dwoma artystami mogło zostać powiedziane coś, co twórczo wpłynęło na realizacje? Nie wiem, czy to w ogóle ma znaczenie.

Możemy sięgnąć do zastanej rzeczywistości nakreślonej utworami lat 60. i 70. XX wieku³. W literackim odwzorowaniu, które stworzył Julio Cortázar, realistyczna dokładność opisu pozwala fantazji tworzyć własne wizje. W Babim lecie 4 (1959) Julio Cortázar w niewidoczny sposób przędzie rzeczywistość, którą później zobaczymy w Powiększeniu ${ }^{5}$ (1966) Michelangelo Antonioniego6 ${ }^{6}$.

Mówimy o tego rodzaju rzeczywistości, w której „w gruncie rzeczy nikt dobrze nie wie, kto opowiada, czy to ja, czy to, co się zdarzyło [...], czy po prostu opowiadam moją własną prawdę"7 _ pisze Cortázar. „Wiemy - dowodził [Antonioni] - że za obrazem kryje się jakaś inna, prawdziwsza rzeczywistość, za nią jeszcze jakaś inna i ponownie za tą ostatnią jeszcze następna itd., aż zaczynamy rozumieć, że istnieje taki prawdziwy obraz rzeczywistości absolutnej i tajemniczej, której nikt nigdy nie zobaczy"8.

Przywołana wypowiedź odnosi się do rzeczywistości w dziele Antonioniego. Richard Wendorf zwraca się do czytelnika z odwołaniem do artykułu Terry'ego J. Peavlera ${ }^{9}$, w którym stwierdza, że Antonioniego ${ }^{10}$ przede wszystkim interesuje kwestionowanie zastanej natury rzeczywistości. Film Powiększenie Antonioniego był analizowany w kontekście różnych zagadnień, moim celem jest zwrócenie uwagi na kontekst sceny tenisowej. Inspiracja zaczerpnięta z filmu Powiększenie Antonioniego oraz realizacji Open Score Rauschenberga stanowi swoistą klamrę interpretacyjną do

\footnotetext{
3 Wybór własny w odniesieniu do pracy artystycznej związanej z tematem balonu.

4 Julio Cortázar, Babie lato, [w:] Opowiadania 1, Warszawa 2009. Oryginał: Las babas del diablo, [w:] Las armas secretas y otros relatos, Madrid 1964.

5 Michelangelo Antonioni, Blow up, 1966.

6 Pietro Ferrua, Blow-up from Cortázar to Antonioni, „Literature/Film Quarterly”, vol. 4, 1976, No. 1, s. 68.

7 Julio Cortázar, Babie lato, [w:] Opowiadania 1, Warszawa 2009, s. 253.

8 Giorgo Tinazzi, Michelangelo Antonioni, Firenze 1985, s. 107-108 (za: Tadeusz Miczka, W Cinecittà i okolicach. Historia kina włoskiego od połowy lat pięćdziesiątych do końca lat osiemdziesiątych XX wieku, Kraków 1993, s. 68).

9 Richard Wendorf, Antonioni's “Blow-up”: Implicated Artists and Unintentional Art, „The Journal of Aesthetic Education”, vol. 16, 1982, No. 1, s. 57-67.

10 „I'm really questioning the nature of reality”, za: Terry J. Peavler, Blow-Up: A Reconsideration of Antonioni's Infidelity to Cortázar, „Modern Language Association. PMLA”, 1979, vol. 94, No. 5, s. 892.
} 
własnej wykładni wykorzystania balonów w sztuce, w tym do własnej pracy artystycznej oraz w szerszej perspektywie w sztuce mediów z autorskiego punktu widzenia.

W pewnym momencie filmu Powiększenie ma miejsce zabawna i dziwna równocześnie scena: grupa młodych ludzi gra tenisowy mecz bez rakiet i piłek. Chodzi o pantomimę - o złudną grę pozorów, która przedstawia przekształcającą się, zmienną rzeczywistość: mechanizm gry rozwija się przed oczami widza obnażony, gdyż brakuje „celu” i „narzędzi” do jej osiągnięcia, opisu czy zdefiniowania. Ta niema scena z punktu widzenia patrzącego wydaje się dziwna, gdyż sam widz nie bierze udziału w fantazjowaniu grających, w „graniu” grania.

Właśnie tę scenę z Powiększenia przywołałam w pamięci, kiedy filmowałam osoby, które rozgrywały ${ }^{11}$ sytuację $\mathrm{z}$ balonami. Był to moment, który nadał nowe znaczenie mojej pracy oraz przyczynił się do tego, iż zrozumiałam, że jest to właściwy kierunek, w którym powinnam pójść dalej. W ten sposób centrum pracy stały się nieważne ścinki zdjęć (filmowania). Balon nie występował w tych ujęciach, natomiast były trzy osoby z żyłkami, które próbowały przygotować balony do ponownego filmowania.

W Balonie, żytce i trzech osobach (2010) Edyty Mąsior kamerą zostało zapisane wydarzenie, które w rzeczywistości było czymś zupełnie innym. Jest to wypowiedź o wielowarstwowej semantyce - wizualny palimpsest.

Edyta Mąsior, „Balon, żyłka i trzy osoby” [kadr], trzykanałowa zsynchronizowana wideoinstalacja, wymiary (minimum) $10 \times 3$ m, 27 min. 32 sek. 12, kolor, 2008-2010.

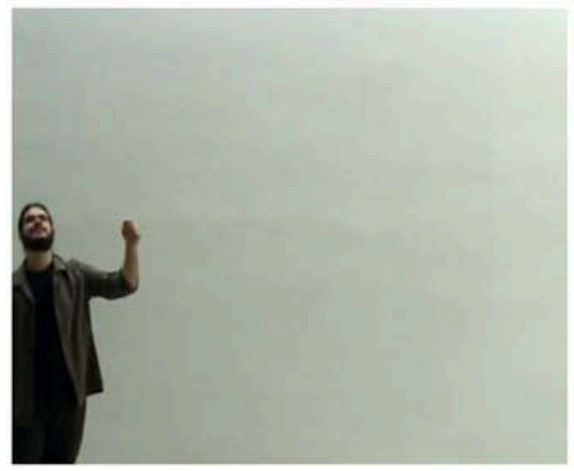

Źródło: archiwum autora

11 Ludus (łac.) - gra, widowisko, zabawa, rozgrywka. 
Pozostało znaleźć to tempo, te ruchy i interwały, które odpowiadałyby charakterowi mojej sceny, aby przewijające się „figury” tworzyły własną przestrzeń i analogiczny czas. Chciałam połączyć grę $\mathrm{w}$ tenisa Antonioniego $\mathrm{z}$ tymi filmowanymi fragmentami poprzez rozwinięcie przed widzem odczucia czegoś dziwnego i nadanie trochę komicznego wymiaru całości pracy. Chciałam pokazać, że „granie” grania jest częścią gry. Przed ustaleniem ostatecznej wersji, końcowej składni artystycznej, pracy pomyślałam o ponownym przedstawieniu tematu, którego brakowało w tych ujęciach - balonu. Tak więc balon pojawia się w oddzielnej, dyskretnej i odrębnej od kadrów z postaciami przestrzeni. Ostatecznie ustaliłam liniową sekwencję, gdzie w jednej z trzech projekcji przedstawiony przedmiot jest trochę powiększony, niemy i niezależny od ruchów, które wykonują trzy osoby w sąsiadujących projekcjach.

Poprzez powtórzenia, pojawianie się i znikanie, analogie ruchów, rzeczy i osób rzeczywistość wdziera się jak coś tajemniczego, dziwnego, czasem tragicznego, współtworząc jej realistyczne odbicie. Mówimy o tego rodzaju rzeczywistości, w której zmiany, które przynoszą czas, przeznaczenie i przypadek, nabierają formy, nadając sens i przybierając znaczenie ${ }^{12}$.

\section{Geneza pracy artystycznej}

\section{Ważne jest, nie abyśmy naśladowali naturę, ale działali tak jak ona. \\ Picasso}

Nie wiem, w jaki sposób powinnam zacząć tę historię. Jeżeli byłoby możliwe powiedzenie: ,ja i moje nie me (czyli nie moje), ale i nieme (czyli bezdźwięczne) balony tworzą iluzoryczną rzeczywistość i jednocześnie jej odwzorowanie, rodzaj dwoistości - prawdziwie zastanej rzeczywistości i jej odwzorowania na poziomie sztuk wizualnych, pozostając na platformie językowego kontekstu"13, to tak opisana wypowiedź i jej złożoność przybliżają sytuację. Mamy do czynienia z przedmiotem balonem, żyłką i trzema osobami.

12 Wyrazy sens i znaczenie $w$ tym artykule są używane w kontekście etymologicznego pochodzenia, nie filozoficznego poglądu. Sens i znaczenie mogą być analizowane w kontekście różnych poglądów filozoficznych (Gottlob Frege, Noam Chomsky). Nadmieniam, że nie jest to moim celem w tym artykule.

13 Edyta Mąsior, Wizualny palimpsest na temat balonu. Wideo Moje nie-me balony. Balon, żyłka i trzy osoby z serii „Balony”, „Annales Universitatis Paedagogicae Cracoviensis. Studia de Arte et Educatione”, 2013, vol. 8, s. $119-122$. 
Podejmując się próby rekonstrukcji genealogicznych początków tej serii artystycznej, muszę powiedzieć, że wszystko zaczęło się od przypadkowego zdarzenia. Zapoczątkowało ono serię artystyczną, proces badań i poszukiwań oraz przyczyniło się do dalszego rozwoju i wytworzenia kolejnych dzieł w zakresie poruszanego tematu. Co to za zdarzenie i jakie ma znaczenie to początkowe doświadczenie? Odpowiedź na te pytania prowadzi do analizy o charakterze badawczym, odtwarzającym rolę i znaczenie przypadku. Początek tego poszukiwania trwał zaledwie kilka sekund.

Chwila odbioru przypadkowego obrazu miała miejsce w lecie 2006 roku na jednej z cykladzkich wysp. Przed moimi oczami (z punktu widzenia obserwatora) rozwinęła się zupełnie przypadkowa scena. Wiał silny wiatr, kiedy nagle dostrzegłam na horyzoncie rozwijające się przede mną nieoczekiwane zdarzenie, które zarejestrowałam za pomocą kamery.

Zbliżając się do plaży Exo Gialos (Santorini, gr. 'E $\xi \omega ~ \Gamma ı \lambda \lambda o ́ \varsigma)$, stałam się odbiorcą/odbiorczynią pewnego obrazu, który składał się z dwóch oddalonych punktów znajdujących się w głębi morza. Na linii ledwo widocznego horyzontu dostrzegłam dwa przemieszczające się obiekty, które początkowo wzięłam za dwie głowy nurków. Nagła, nieoczekiwana obecność tych dwóch znaków w morzu wywołała we mnie próbę ich odkodowania (rozpoznania), zidentyfikowania, jak i zdefiniowania nieokreślonych dotąd obiektów. Zdziwiło mnie tempo ich zbliżania się w moim kierunku, a wraz z moim podejściem do brzegu zdałam sobie sprawę, że nie są to dwie głowy nurków, ale dwa niebieskie balony połączone żyłką. 
Edyta Mąsior, Dwa niebieskie balony [kadr], jednokanałowa instalacja audiowizualna, wymiary (ok.) 4 × 3 m, 7 min. 55 sek., 2006 .

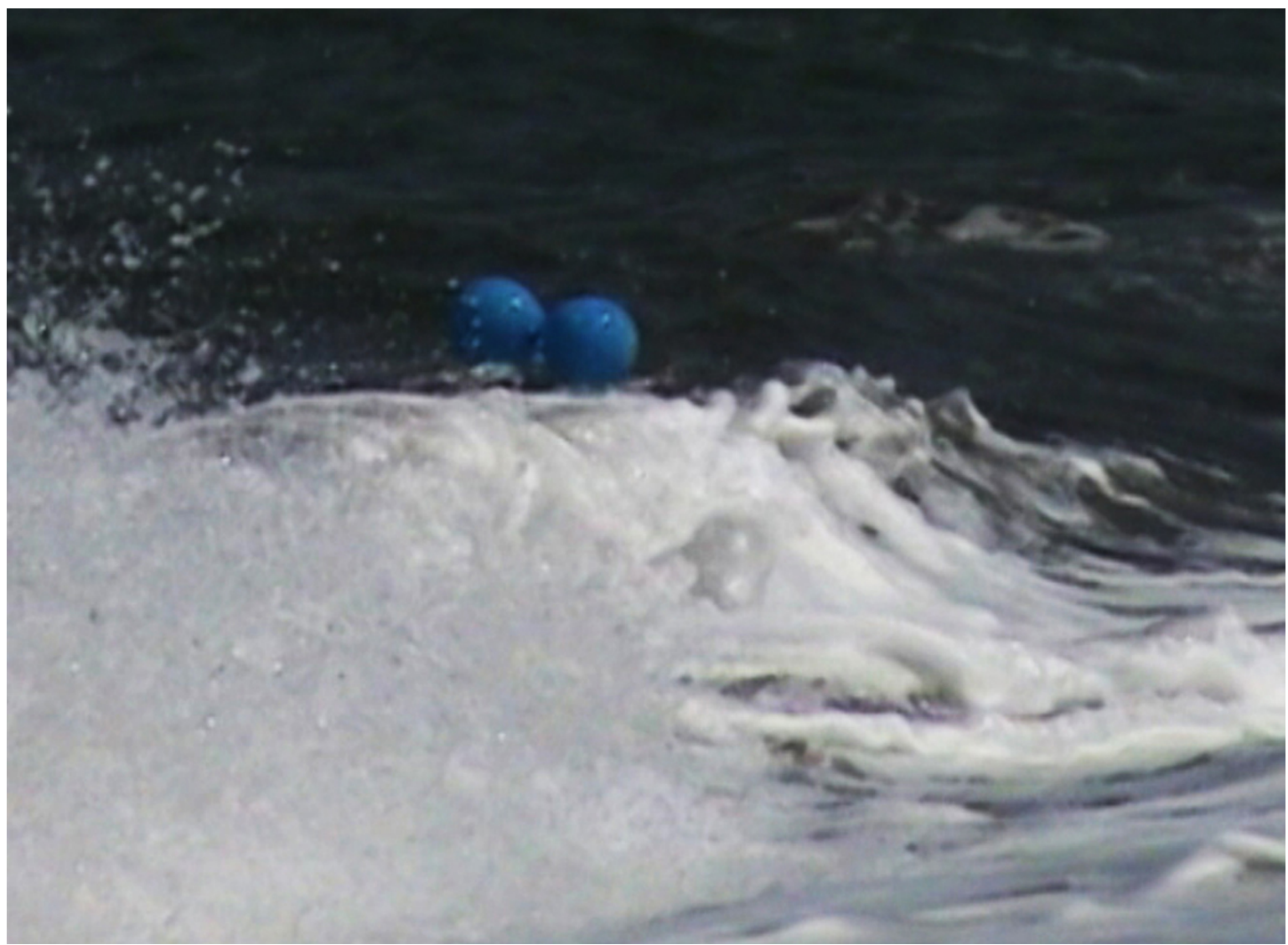

Żródło: archiwum autora

Przywołuję w pamięci chwilę (kadr z wideo), która niczym migawka w aparacie (technicznie utrwalony moment) uruchamia fragment wykadrowanej rzeczywistości (plan kadru), w której ani ramka (plan w obiektywie), ani przemijający czas (czas trwania filmowania) nie wyodrębniają chwili (repetytywny obraz oraz zwolnione tempo nadane w postprodukcji), a obraz uruchomiony falami (falami morza) stanowi korpus dla rzeczywistości (wydarzenie, które miało miejsce) i jej odwzorowania (zapis na kamerze). Fragment powietrza $\mathrm{z}$ balonem (kadr z planu zdjęciowego) zostaje odtworzony za pomocą balonu $\mathrm{z}$ powietrzem (seria, cykl dzieł artystycznych Balony realizowana i upowszechniona od 2010 roku do chwili obecnej) oraz staje się przyczynkiem do powstania i analizy pracy z nadrzędnym tematem: balon. Poniższa analiza jest próbą odpowiedzi na pytanie: „Co robi balon?”, odnosi się do pytań, które powstały w trakcie mojej pracy nad tą serią. Poprzez wielość pytań zapraszam do dyskusji. 
Zdarzenie to, jak również moja pytająca postawa przybrały formę serii złożonych pytań: „Co to jest za obiekt?”, „Co to za przedmiot?”, „Co to jest przedmiot w ogólnym znaczeniu?”, „Kto jest odbiorcą?”, „Kim jest odbiorca?”, „Kto to jest odbiorca?”, „Co to jest znak?”, „Co to jest symbol?”, „Jakie jest znaczenie rozpoznania i identyfikacji jakiegoś sygnału wzrokowego czy znaku?”, „Jakie znaczenie ma przedmiot taki jak balon?”, „Jakie są jego cechy charakterystyczne?”, „Co nazywamy balonem, który nabiera symbolicznego znaczenia, eksploatowany zarówno jako symbol, jak i znak?”, „Co to jest balon, czyli jakiś materiał, który zawierając w sobie substancję nieuchwytną i niematerialną, dzięki niej samej staje się określonym przedmiotem?”, „Czy możliwe jest zbadanie, w jaki sposób balon interreaguje z otoczeniem?”, „Co się dzieje, kiedy jakiś balon spotyka drugi balon lub jakąś osobę?”, „Jaki jest jego stosunek do przestrzeni, miejsca lub otwartego środowiska?”, „Czym jest to coś wieloznacznego i zarazem konkretnego jako przedmiot - jakiś obiekt, jeden oddech, koło, kula?".

Celem moich poszukiwań, analizy o charakterze badawczym - która zawiera początkowy, oryginalnie empiryczny charakter obserwacji - jest zapis i opis tożsamości (charakteru) przedmiotu, jakim jest balon, zwrócenie uwagi na środowisko, w którym rozwinęło się artystyczne - tak moje, jak i innych - poszukiwanie, pogłębienie i poszerzenie tematu w celu określenia przedmiotu, jakim jest balon, oraz rozróżnienie jego zależności, które dokonują się poprzez jego funkcjonowanie, a także określenie, co jest owym ,jest” (gr. cíval) balonu w ogóle. Poszukiwania w obrębie tematu prowadzą do korzeni owego ,jest” balonu, które zarazem stanowi owo ,jest” (niem. zeine) kreatywności - ulotną wartość, która jest związana z procesem oddychania (powietrze zawarte w balonie).

Nikos Navridis zawarł temat balonu w pracy zatytułowanej Szukając miejsca (ang. Looking for a Place, 1999). Rosa Martinez opisała tę pracę w literacki sposób, niczym rytm fal determinujących powtarzalne ruchy morza, tak jak i ,naprzemienne ruchy oddychania określające nasze istnienie [...]. Oddychając, pochłaniamy cząstki wszechświata, przekształcając je w nas samych, w jedynym i wyłącznym celu wydalania ich z powrotem pod postacią oddechu, potwierdzając i podkreślając rytm i napięcie każdego naszego nastroju"14. Jedno (albo więcej) tchnienie może napełniać balon, dając początek wewnętrznemu światu, który następnie zawiera się w zewnętrznym świecie. To, z czym mamy do czynienia, to przepływ. Nie ma znaczenia, czy to realnie chodzi o jeden oddech, czy o ich wielość, chodzi o działanie.

14 Rosa Martinez, Nikos Navridis, 3. katalog nagrody DESTE, Fundacja DESTE (tłum. własne), Ateny 2003, s. 27. Nikos Navridis, Szukając miejsca [ang. Looking for a Place] (1999), czterokanałowa wideoinstalacja, kolor, dźwięk, 17 min. 24 sek. 
Balon jest równocześnie znaczonym i znaczącym, mianowicie zawiera (powietrze) i jest zawarty w szerszej przestrzeni (w powietrzu). Etymologicznie wyraz „balon” pochodzi od włoskiego pallone $^{15}$ (wielkości palla piłki) i oznacza przestrzenny kształt, najczęściej kulisty z elastycznej powłoki, która jest wypełniona powietrzem lub gazem, o zmiennych wymiarach. Charakteryzujące go właściwości ujawniają się, gdy przedmiot wypełniony gazem lub powietrzem staje się geometrycznego kształtu kulą, sferą czy jest określony kształtem. Balon może być dowolną formą, zazwyczaj przestrzenną. Balon jest elastycznym tworzywem wypełnionym powietrzem, gazem (np. helem), może być przezroczysty albo kolorowy, spełnia funkcję przedmiotu do zabawy i rozrywki. Balony tworzą lub przyczyniają się do stworzenia poczucia odrębnego otoczenia, nadając nowe znaczenie pojęciu niewypełnienia ( $\mathrm{w}$ kontekście przestrzeni). Jest to materiał, który jak skóra zamyka w sobie, ukrywa i odkrywa stale zmieniającą się wieloznaczność oddechu.

Przedmiot o zmieniającej się wielkości można ocenić jedynie w warunkach charakteryzującej go przekształcalności:

[...] według Arystotelesa istnieją dwa rodzaje przekształcania się: pierwszy powrotu do stanu początkowego, jakie ma miejsce w przypadku przejścia od dnia do nocy i powrotu do dnia, i drugiego rodzaju przekształcanie się bez odwrotu, jak na przykład przejście od wieku dziecięcego do człowieka dorosłego' ${ }^{16}$.

W pierwszym przypadku, powrotu do stanu początkowego, przekształcanie się balonu identyfikuje się z funkcjami, które odwzorowują się w nadmuchiwaniu i wylatywaniu powietrza z balonu. Zamiana ma charakter przestrzenny: początkowo bezkształtna forma, płaski obiekt (przedmiot), poprzez oddech (może też mechanicznie) zmienia się w formę sferyczną. Ponadto geometryczny kształt balonu, tylko dlatego że nie jest stałą materią, może doświadczać różnorodnych zmian w formie zależnych od przestrzeni, w której się znajduje. Ciało czy obiekty, które go otaczają, lub jakaś ograniczona przestrzeń mogą mieć wpływ na zmianę jego właściwości. Drugi przypadek ma miejsce w momencie zamiany bez możliwości powrotu do stanu początkowego, kiedy nadmuchany balon pęka. W ten sposób traci formę pierwotnego przedmiotu. Obiekt nagle znika i jest to fakt, który pokazuje jego szczególny charakter - jak bąbel czy bańka mydlana, balon jako przedmiot przemienia się - przybierając różnorodne formy. Przejścia z jednego stanu do drugiego odpowiadają jego właściwościom.

\footnotetext{
15 Giorgio Faggin, Vocabolario Della Lingua Friulana, t. 1, Udine 1985, s. 49.

16 Navridis, La Biennale di Venezie, 49, Ateny 2001, s. 25.
} 
TOM 1, NR 1 (2020)

Balon jest przedmiotem, który jest stale charakteryzowany poprzez dualność, połączenie (elastyczność - napełnianie się), działając w ten sposób niczym bliźniacza forma. Przedmiot oddech „uwięziony” w elastycznej przestrzeni przemienia się i przyjmuje właściwości i znaczenie nowego przedmiotu (nowego oddechu). Początkowy przedmiot, w efekcie wdechu, wydechu lub jego kompresji, jest nagrywany za pomocą kamery wideo i zostaje przeniesiony do artystycznego obszaru działań i badań. Balon jako przedmiot oddziela się wtedy od jego pierwotnych funkcji użytkowych i jego zwyczajowo spotykanych cech charakterystycznych, staje się przedmiotem do wytwarzania obrazu, a może i nowych znaczeń: przestaje być handlowym produktem.

Kiedy jeden przedmiot ${ }^{17}$ sztuki oddziela się od jego początkowego miejsca, jego pierwotnego czasu i jego oryginalnego przeznaczenia [...], wówczas uwalnia się i pozbawia wszystkich jego początkowych znaczeń18.

Związek znaczeń, symboli z rzeczywistością, jak wyraża to Wittgenstein w Tractatus Logico - Philosophicus, mógłby oznaczać przeniesienie z filozoficznego wymiaru do obszaru sztuki. „Ponieważ jedno zdanie, które coś mówi, jest jakimś obrazem rzeczywistości, jak i wyrażenie wskazuje na jego znaczenie. Dlatego iż istnieje związek pomiędzy symbolami na papierze i stanem świata zewnętrznego. Dlatego że forma obrazowania jest formą rzeczywistości”. Dlatego, jak mówi Wittgenstein, świat jest jednością wydarzeń, „przeciwko umysłowi zadręczanemu przez językowe środki wyrazu"19.

\section{Od przedmiotu do języka}

Ryba jako ostatnia wie, że żyje w wodzie.

Niepewne źródło 20

Poza symbolicznym znaczeniem balonu jako przedmiotu samego w sobie (o ile w ogóle może występować coś takiego jak znaczenie przedmiotu poza jego symbolicznym porządkiem), to, co ma większe znaczenie, to zarys pierwotnego doświadczenia, czasowo-miejscowe kontinuum obserwacji, moment, w którym balon stał się elementem w korelacji symbolicznego porządku mojej percepcyjnej gospodarki jako podmiotu tego tematu. Co oznacza owo początkowe doświadczenie? Co to znaczy obserwować coś? Jakie jest miejsce obserwującego i jego związek z tym, co obserwowane? I jeszcze jedno: czy przedmioty mogą występować poza polem obserwacji?

17 Obiectum (łac.).

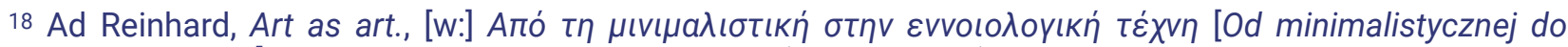
konceptualnej sztuki], red. Nikos Daskalothanasis, ASFA (tłum. własne), Ateny 2006, s. 58.

19 Navridis, La Biennale di Venezie, 49, Ateny 2001, s. 23.

20 Chiński aforyzm (niepewne źródło), za: Lynn Segal, The Dream of Reality, New York 2001, s. 6. 
$\mathrm{Na}$ początku te dwa balony mnie zaskoczyły. Później próbowałam zreprodukować, czyli odtworzyć to początkowe wydarzenie, rekonstruując je. Nagrywałam kamerą balony w podobnych warunkach, a później badałam różne możliwości będące alternatywnymi formami istnienia tego samego przedmiotu. To początkowe doświadczenie było impulsem do budowy wariantów tej samej rzeczy. Były to wariacje problemowe, powtórzenia tego, co jednocześnie było tym samym i czymś innym, samym w sobie, znaczonym i znaczącym. Jedno zdarzenie, które pozostawia trwały ślad w umyśle, za każdym razem jest różnicowane przez powtarzanie, pomimo że pozostaje tym samym (,podobnym”). Derridy różnica... Sama w sobie różNICa...21

$\mathrm{Z}$ punktu widzenia zewnętrznego obserwatora zdarzenie $\mathrm{Z}$ balonami było po prostu przypadkowym incydentem. Jednak to, co wydaje się zwykłym przypadkiem, nie jest niczym innym jak wynikiem sekwencji wydarzeń, których obserwator nie jest w stanie rozszyfrować22. Wiatr wiejący w określonym kierunku kieruje gdzieś jakieś balony: to wydarzenie wydaje się przypadkowe, ale takie nie jest. Chodzi o złożony system nieokreślonych czynników naturalnych, których nie jesteśmy w stanie odszyfrować. Ponadto istnieją niezidentyfikowane czynniki, które skierowały mnie do tej konkretnej plaży (Exo Gialos, Santorini), jak również fakt zauważenia odległego ruchu nieokreślonych przemieszczających się przedmiotów w morzu. Jest to szereg specyficznych alternatywnych czynników, których nie możemy zidentyfikować, bo gdybyśmy byli w stanie przewidzieć i odkodować zaistniałą sytuację, zbiegłaby się ona $\mathrm{w}$ czasie $\mathrm{z}$ samym przebiegiem zdarzenia. Tym jest właśnie zbieg okoliczności w tym przypadku. Jest logicznym ciągiem wydarzeń, które doprowadziły do tej zbieżności, okoliczności (mojego) pójścia na plażę i przemieszczania się balonów (przede mną) w pewnej odległości, razem z uwagą, którą na nie skierowałam w tamtym momencie. Owo wydarzenie jest właściwie czasoprzestrzennym zbiegiem okoliczności, który z punktu widzenia obserwatora nie może być odczytany inaczej, jak tylko jako przypadkowy, pomimo że samo użycie słowa „przypadek” deterministycznie przywołuje nieuchronność w przeważnie niedeterministycznym świecie, w którym miało miejsce to wydarzenie.

21 Jacques Derrida, 0 gramatologii, tłum. Bogdan Banasiak, Warszawa 1998. Andrzej Marzec w artykule Différance Derridy. Czy błąd daje się (wy)tłumaczyć? („Przekładaniec. A Journal of Translation Studies”, 2011, nr 24, s. 263-280) zwraca uwagę na powstałe propozycje translatorskie w języku polskim, w tym „róż(nic)ość" (Bogdan Banasiak), „różnia” (Joanna Skoczylas), „różNICa” (Tadeusz Sławek), "gra-na-zwłokę-oróżnicę" (Stanisław Cichowicz).

22 Średniowieczny aforyzm „Natura nie czyni skoków”, do którego odwoływał się Gottfried Leibniz (zob.: Alexander Baumgarten, Metaphysics: A Critical Translation with Kant's Elucidations, Translated and Edited by Courtney D. Fugate and John Hymers, Bloomsbury, 2013, Preface of the Third Edition, 1750, s. 79). 
Umowny charakter świata, jak i deterministycznie kodyfikująca funkcja ludzkiego poznania są dwiema niełączącymi się rzeczami.

„Przypadkowość” jest pojęciem, które my sami stworzyliśmy, aby opisać płynność rzeczy w otaczającym nas świecie. Za pomocą słów, pojęć, znaczeń i punktów w końcu, które nie są niczym innym jak metaforycznymi kształtami wynikającymi z poznawczego charakteru człowieka, ograniczając płynność i kosmologiczny chaos, nadając stabilność, a więc i uspołecznienie, określamy stałe punkty w celu ograniczenia płynności pola zaburzeń, które nazywamy otaczającym nas światem.

Francisco Varela i Humberto Maturana ${ }^{23}$, chilijscy neurobiolodzy, określają to, co odbieramy jako środowisko w ogólnym znaczeniu jako pole zaburzeń. My, jako pojedyncze jednostki, odbieramy zaburzenia, które - chcąc nimi zarządzać - odnosimy do kształtów i poprzez ustanowienie związków przyczynowo-skutkowych (pomiędzy pojęciami/znaczeniami i rzeczami) uczymy się orientacji w świecie, nadając zewnętrzną ciągłość jego podstawowej niespójności. Poprzez ciągłość i powtarzalność utrwala się znaczenie, a koncepcja umacnia się jako prawda i odtąd jest interpretowana jako owa rzecz sama w sobie. Wszystkie punkty są metaforycznymi znakami, kształtami. Określamy stałe punkty, żebyśmy mogli zmniejszyć płynność w polu zaburzeń, które nas otacza. Wypowiadając słowo „balon”, zapominamy, że chodzi o jeden wyraz, umowny produkt naszego ogólnoludzkiego pojmowania, ustalenia, jednej umowy, która łączy rój cząsteczek składających się na przedmiot $\mathrm{w}$ jeden poznaniowo zrozumiały kształt - przedmiot balon. Za pomocą takiego rozumowania balon przestaje być wieloznacznością, staje się językowo tożsamy

23 Humberto Maturana, Reflections on My Collaboration with Francisco Varela, „Biology of Cognition, Constructivist Foundations", vol. 7, 2012, No. 3, s. 155-164; Alberto Paucar-Caceres, Roger Harnden, Commentary on the Separate Prologues by Humberto Maturana and Francisco Varela to the Second Edition of 'De Máquinas y Seres Vivos-Autopoiesis: La organización de lo vivo'- Twenty Years After, „Systems Research and Behavioral Science Syst. Res.", 2011, No. 28, s. 577-580; Michael Straeubig, On the distinction between distinction and division, „Technoetic Arts: A Journal of Speculative Research”, vol. 13, 2015, No. 3, s. 245-251. 
i sklasyfikowany ${ }^{24}$, ale to „coś” nie jest balonem, jest metaforą jednej rzeczy będącej balonem, ponieważ my tak ją nazwaliśmy. Ze względu na przyzwyczajenia i powtarzalność zapominamy, że to coś, ta rzecz, jest metaforycznym kształtem i jest interpretowana jako rzecz sama w sobie.

U podstaw każdej poznaniowo-gnostycznej energii leży zawsze ten sam fundamentalny proces, jeden mechanizm ogólnego poznania: centralny układ nerwowy, odbierający bodźce lub podrażnienia poprzez narządy zmysłu, które za pomocą nerwowych sygnałów czy impulsów są przekazywane do mózgu, aby mogły być tłumaczone kolejno na postać form, dźwięków, obrazów, w celu uzyskania materiału o charakterze poznawczym. W ten sposób odbieramy zawsze zakodowane informacje. A otrzymywane wiadomości nigdy nie są tą formą, która znajduje się tam czy gdzieś indziej na zewnątrz, ale to te, które my postrzegamy jako zamknięte systemy: już za pośrednictwem odebranych obrazów, przenośników rzeczy, które następnie poddane obróbce logiki, czyli obróbce gramatyczno-składniowej, budują w ten sposób jeden sieciowo-neuronowy, najbliższy nam obraz świata (nie taki, jaki on jest, ale taki, za jaki go uważamy). W ten sposób tworzona jest jedyna możliwa dla nas struktura świata zewnętrznego: świat symboliczny.

Wobec przypadkowego pojawienia się dwu balonów w morzu mój umysł został zmuszony do wyjaśnienia tego, co odebrał receptorycznie, wprowadzony został w ten sposób porządek związku przyczynowo-skutkowego: początkowo myślałam, że balony były głowami nurków (pierwsza identyfikacja - determinanta). Od systemu poznawczego zostały następnie wysłane pytania, które miały do czynienia z rodzajem podobieństw i zasadami rozpoznawania tożsamości, a których byłam nieświadoma. Kiedy, znowu nie wiedząc o tym, dokonałam bardziej wysublimowanej i wyabstrahowanej formy obserwacji, zinterpretowałam, iż chodzi o dwa balony, a nie o głowy nurków. Poprzez pewnego rodzaju (zawsze jednorodny) „wzorzec rozpoznawania” nadałam logiczną składnię zjawisku, które rozwijało się przede mną, przypisałam mu właściwe orzeczenie (głowa). Mechanizm poznawczy człowieka opiera się na relacjach podobieństw i różnic przeciwstawnych sobie.

24 De Saussure opisuje język jako mechanizm redukcyjny. Mówi, że język jako całość obejmuje sam siebie, będąc początkiem klasyfikacji. To, że jest całością, oznacza, że sam w sobie język zawiera słowo język, słowo, które może opisać samo siebie. To, co kategoryzuje język, jest niezróżnicowane jako rzeczy, których doświadczamy, a które de Saussure nazywa „niejednorodnością". Język razem ze znaczeniem, jakie mu daje de Saussure, działa jako dostawca znaczeń dla rzeczy, które ze swej natury nie mają jedności. Język jest redukcyjnym, naprowadzającym mechanizmem, który zamienia złożone moduły $w$ jedną całość. W niezróżnicowane fragmenty wprowadza różnice. Jedność języka jest na poziomie czystej abstrakcji (pure abstraction), gdzie istnieje tylko ujemna różnica: jeden znak jest zrozumiały tylko w konfrontacji z samym sobą, gdy ten nie jest tym samym, ale innym (mężczyzna jest niekobietą, a kobieta jest niemężczyzną). 
Świat na zewnątrz (jego fizyczna przestrzeń) jest zasadniczo wynikiem przypadkowości: my jesteśmy tymi, którzy określają prawa i standardy tego świata, przekształcając go w świat przyczynowo-skutkowy. Rzeczy w świecie, na zewnątrz (naszego systemu poznawczego), są więcej niż przypadkowe, i konieczne, poza rozpoznawaniem granic: my jesteśmy tymi, którzy wprowadzają różnice, zmniejszając niezróżnicowane poszczególne tożsamości. Postrzeganie rzeczywistości zawsze odnosi się do ustalana limitów, podziałów i zróżnicowań, wprowadzania przeciwstawnych par: przypadkowe/niezdeterminowane przyczynowe/konieczne, prawdziwe/nieprawdziwe. Dlaczego? Tylko bowiem w oparciu o związek przyczynowo-skutkowy możemy żyć. Kiedy uznajemy coś za konieczność, równocześnie rozpoznajemy to jako coś, przyczynę efektu lub przyczynę i skutek.

„Dostrzec coś” nie oznacza po prostu „widzieć coś”. Obserwacja obejmuje zasadniczo proces kodowania językowego. Nie możemy obserwować z wyłączeniem kontekstu językowego ${ }^{25}$. Nawet siatkówka oka nie funkcjonuje niezależnie od języka. Dla Heinza von Foerstera, Vareli i Maturany, Watzlawicka - wybitnych przedstawicieli epistemologicznej szkoły funkcjonującej pod nazwą „radykalnego konstruktywizmu” - teoria obserwatora jest nierozerwalnie związana z zagadnieniem kodyfikowania poprzez język, ponieważ pozajęzykowo przedmioty pozostają dla człowieka niedostępne. To, że rozróżniamy przedmioty, identyfikując je, nie jest związane tylko z funkcjonowaniem oka, ale również języka. Język, z gramatyczno-składniową strukturą, łączy i rzeczy, i przestrzeń w całości, wewnątrz których one funkcjonują. Język, poprzez jego logiczną strukturę, rozwiązuje niejasności, niejako rozwijając zarazem inne, bardziej ryzykowne (np. moje „niedopatrzenie” w analitycznym podążaniu w pierwszym „,zobaczeniu” głowo-balonów). Kiedy coś widzimy, rozpoznajemy to jako przedmiot, dlatego że nasze myślenie jest w całości oparte na

25 "Język jest środkiem poznawczym naszego istnienia. Wszystko, co może być powiedziane, jest powiedziane przez obserwatora do innego obserwatora, który może być nim lub nią samą", za: Lynn Segal, The Dream of Reality (tłum. własne), New York 2001, s. 6. 
języku: każdy obiekt jest obiektem logicznie skonstruowanego podążania myśli26. Obserwator żyje w języku, dokładnie w ten sam sposób, w jaki ryba żyje w wodzie ${ }^{27}$. Rzeczywistość rozpoznawalna pozajęzykowo nie może istnieć. Nic nie jest rozpoznawalne poza polem obserwatora, poza jedną rzeczą: samym obserwatorem. Nikt nie może obserwować sam siebie. Jak powiedzieliby Varela i Maturana, nikt nie może być równocześnie wewnątrz i na zewnątrz obszaru obserwacji, innymi słowy, nie można być zarówno obserwatorem i obserwowanym. To, co robi obserwator, to stałe wprowadzanie różnic, tak aby diametralnie oddzielić jedną rzecz od drugiej, porządkowanie nieprzerwanego przepływu danych, jak i chaosu zdarzeń, które składają się na niezróżnicowany splot, jakim jest świat.

Jedyną rzeczywistością jest rzeczywistość strukturalnych powiązań centralnego układu nerwowego w ścisłym związku z otoczeniem. Świat (tam) na zewnątrz jest niezróżnicowany. Nie ma w nim różnic, podmiotów, faktów i zdarzeń czy oddzielnych przedmiotów. Jedyna rzecz, jaka istnieje, to według Deleuze'a ${ }^{28}$ intensywne wieloznaczności (korelatory), nieustannie zmieniające się systemy natężeniowe. Cokolwiek dzieje się poza układem nerwowym człowieka, jest nie do zidentyfikowania: nie istnieje nic poza stałą płynnością czy jednym chaosem. Cokolwiek dzieje się poza układem nerwowym człowieka, nie istnieje jako fakt czy zdarzenie. Tam (na zewnątrz) panuje to, co niezróżnicowane. Układ nerwowy człowieka jest tym, co poprzez swoją strukturę operacyjną jest ukształtowane tak, aby dostarczać zawsze stabilną rzeczywistość. Stałą podstawę (fundament), na której stoimy na świecie, tworzymy my sami poprzez formatywne działanie złożonego systemu nerwowych sieci, które poprzez klasyfikacje i identyfikacje bodźców nadają formy rzeczom. W takim znaczeniu podstawowym zadaniem centralnego układu nerwowego jest gromadzenie wieloznaczności i przekształcanie w jedności. Niezróżnicowany chaos (chaosmos) jest nie do

${ }^{26}$ „Język jest metaforą w tym sensie, że nie tylko przechowuje, lecz również przenosi doświadczenia z jednej formy w inną. Pieniądze są metaforą w tym znaczeniu, że przechowują umiejętności i siłę roboczą, a także zastępują jedną umiejętność drugą. Jednak zasada wymiany i przenoszenia, czyli metafora, leży w zdolności naszego umysłu do nieustannego przekładania jednego zmysłu na drugi. Robimy to w każdym momencie naszego życia. Ceną wszakże, którą płacimy za konkretne techniczne narzędzia, czy to koło, alfabet, czy radio, jest to, że te potężne rozszerzenia zmysłów tworzą zamknięte systemy. Nasze prywatne zmysły nie stanowią zamkniętych systemów, lecz są nieustannie przekładane jeden na drugi w doświadczeniu, które nazywamy świadomością. Nasze rozszerzone zmysły, narzędzia i technologie przez wieki były zamkniętymi systemami niezdolnymi do wzajemnego oddziaływania lub zbiorowej świadomości", za: Marshall McLuhan, Wybór tekstów, red. Eric McLuhan, Frank Zingrone, Poznań 2001, s. 142 (wyróżnienia za oryginałem).

27 "Observers live in language the way fish live in water”, za: Lynn Segal, The Dream of Reality, New York 2001, s. 6.

28 Krzysztof Kościuszko, Pojęcie - idea - problem w „Różnicy i powtórzeniu” G. Deleuze’a, „Humanistyka i Przyrodoznawstwo", 2004, nr 10, szczególnie s. 74-76. 
zmierzenia, nie ma numeru ani wymiaru: centralny układ nerwowy jest tym, który porządkuje tę niezidentyfikowaną strukturę za pomocą receptorów i przekształca je w zindywidualizowane i jasno określone formy.

Takie epistemologiczne podejście ma następujące logiczne konsekwencje: zewnętrzna rzeczywistość jest zmienna i płynna, pomimo że jest uwarunkowana przez z góry określone i odpowiednie prawa. Jesteśmy zamkniętymi, autonomicznymi żyjącymi systemami, oddziałującymi $\mathrm{z}$ otoczeniem. Fakt, że oddziałujemy z otoczeniem, w żadnym stopniu nie znaczy jednak, że mamy świadomość tego, co dzieje się tam (na zewnątrz). Wiedza o świecie jest tworzona poprzez interakcję. Inny, zewnętrzny, niezależny od nas świat jest po prostu wyobrażeniem. Nie odkrywamy świata, ale go wynajdujemy. I tak dochodzimy do drugiej logicznej konsekwencji: dostrzec 29 coś nie oznacza, że odkrywamy coś, ale nadając czemuś uwagę, wynajdujemy ${ }^{30}$.

My, jako ludzie żyjący w kulturze zachodniej, nauczyliśmy się mieć bardzo specyficzny (konkretny) stosunek do rzeczy: jesteśmy stojącymi istotami, rozumnymi i mamy bezpośredni związek z otaczającym nas światem. „My i wszystkie zwierzęta wyższego rzędu jesteśmy dwubocznie symetryczni: mamy bowiem przód (głowę) zawierającą mózg, a także preferowany kierunek ruchu (naprzód)" 31. W postrzeganiu rzeczy ma duże znaczenie to, że oddzielamy to, co widoczne, od tego, co niewidoczne, tak jak to, że oddzielamy to, co jest rzeczywiste, od tego, co jest nie rzeczywiste, przejrzyste od nieprzejrzystego ${ }^{32}$. Nauczyliśmy się działać w obrębie warunkowych nadrzędno-podrzędnych korelacji: istnieje jedno ja (gr. $\varepsilon \gamma \omega ́$ ) jako podmiot percepcji i istnieje coś tam dalej, jako przedmiot percepcji. Nauczyliśmy się myśleć w kategoriach przedmiotu i podmiotu, czyli alternatyw i sprzeczności.

Wydarzenie na plaży nie może być niczym innym jak tylko zdarzeniem spostrzegania. „Odkrywam coś” oznacza, że znajduję coś, co jest tam (na zewnątrz), znajduję to jako coś nowego,

\footnotetext{
${ }^{29}$ паратпри் (gr.).

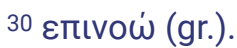

31 Sacks Olivier, Rzeka świadomości, Poznań 2018, s. 73.
}

32 W 1971 roku Marshall McLuhan zaproszony przez Edwina Newmana do radiofonicznego wywiadu dla NBC, analizując pytanie, dlaczego medium jest przekaźnikiem, przywołał przykład pewnych Indian w Ameryce, którzy malując, nie malują tylko na płasko zastanej powierzchni, ale kontynuują też od dołu (na przykład malując stół, malują go także od spodu), nie zwracając uwagi na zastany kontekst odbierania informacji przestrzennej na takiej zasadzie, na jakiej my, zachodni ludzie, zwykliśmy się wykształcać w pojmowaniu świata (za: http://www.ubu.com/sound/mcluhan.html [dostęp: 22.06.2009]). 
więc samo w sobie jest nieznane. „Wynajduję coś” (spostrzegam) oznacza coś zupełnie innego. Dokładnie dlatego, że to ja sama zaobserwowałam to zdarzenie i nadałam mu znaczenie. Nadałam mu sens, wybierając właśnie to, a nie coś innego, jako to obserwowane. Jeżeliby w tamtej chwili nie było tam mnie jako obserwatora, to wydarzenie nie miałoby znaczenia. Jak powiedziałby Leibniz, „,bez zdarzeń nie ma ani czasu, ani przestrzeni”33.

Cokolwiek znajduje się poza polem obserwatora, nie ma dla niego znaczenia. W ten sposób ja sama wybieram i wytwarzam coś, co jest morfologicznie (strukturalnie) konkretne na drodze receptorycznych redukcji. Otoczenie jest polem zaburzeń (wizualnych, akustycznych), które wpływając do zakresu naszej percepcji, muszą zostać sklasyfikowane, uporządkowane, aby zostały rozpoznane, zeskanowane, w celu nadania im właściwego znaczenia. W ten sposób każdy człowiek jest z biologicznego punktu widzenia, czyli z natury jego samego, artystą (twórcą), ponieważ wytwarza. To dlatego, jak pisze Nietzsche w O prawdzie i kłamstwie w pozamoralnym znaczeniu ${ }^{34}$, bierze jakiś wątpliwy materiał i przekształca go w coś innego. Odbiera bodźce, które nie mają nazwy, i wytwarza z nich światy. Fakt, który oznacza, że układ nerwowy może być postrzegany jako pierwszy model artystycznego działania.

Działalność artystyczna w moim przypadku, ale i w każdym przypadku, nie rozpoczęła się w momencie, kiedy zaczęłam nagrywać balony. Całe zdarzenie - od pierwszej chwili do ostatniej jest jedną i tą samą rzeczą, jedną złożonością pewnego całościowego procesu. Pojawienie się oddalonych znaków, balonów, to, w jaki sposób ja je odebrałam i przetworzyłam tę scenę na wstępnym etapie, sposób, w jaki mój system nerwowy połączył różne bodźce w jeden moduł, w jeden obraz, wszystkie te elementy są zasadniczo podstawą tego samego działania, budowania (struktury) dzieła. Praca artystyczna nie zaczęła się od momentu jej produkcji. Zaczęła się od pierwszych nanosekund, w których układ nerwowy odebrał bodziec ukierunkowany gdzieś w świecie.

\footnotetext{
33 Michał Heller, Elementy filozofii przyrody, Kraków 2014, s. 37.

34 Friedrich Nietzsche, Pisma pozostałe 1862-1875, Kraków 1993, s. 181-199.
} 
Edyta Mąsior, Różne warianty nocy [kadr], wielokanałowa instalacja audiowizualna, wymiar (min.) 4 × 3 m [różny czas trwania], 2011.

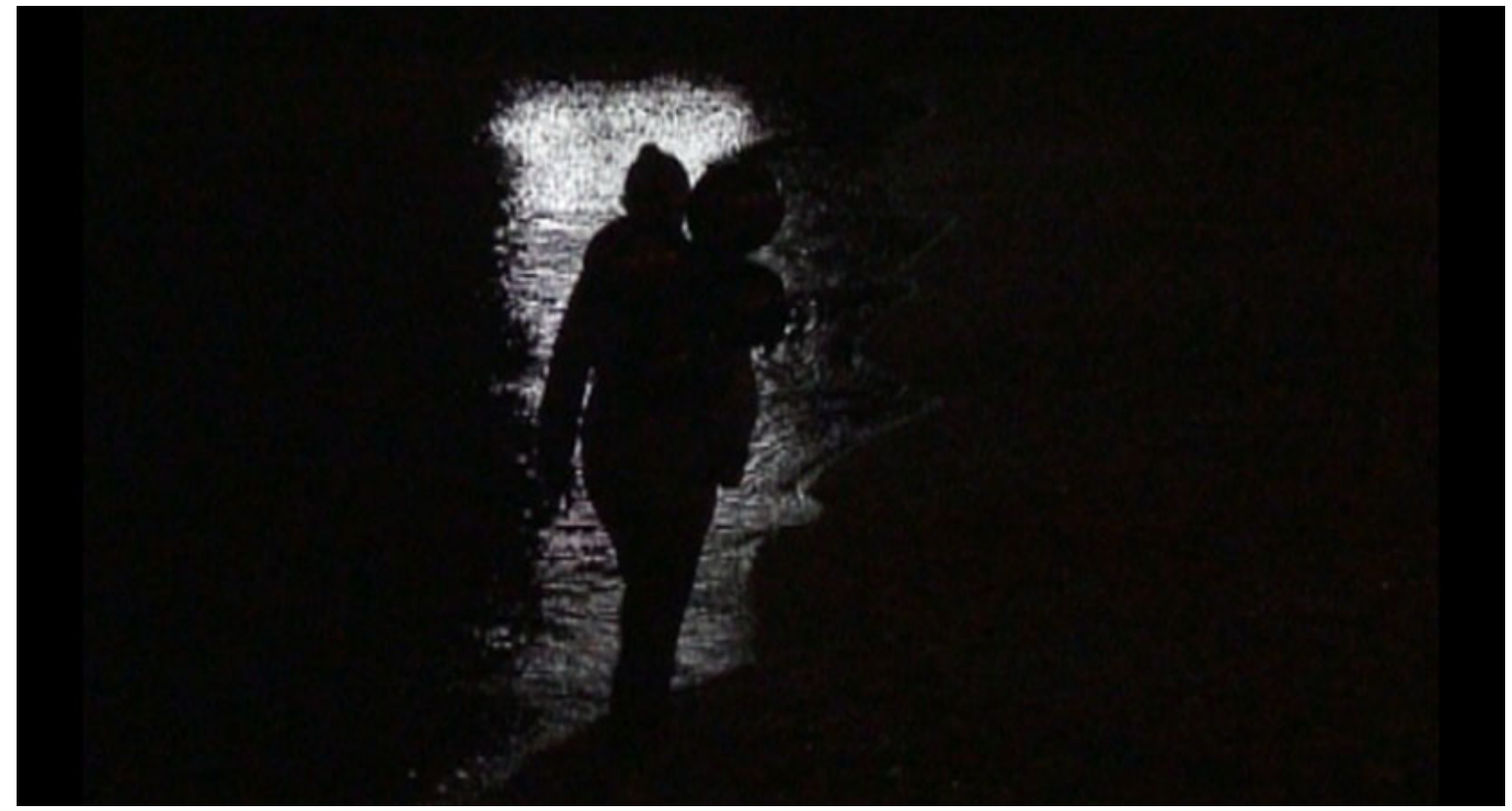

Źródło: archiwum autora

\section{Działanie w dwóch odsłonach ${ }^{35}$}

Gra (le jeu) to jest czynność ludyczna, ale i funkcjonowanie mechanizmu36.

Roland Barthes

Michelangelo Antonioni w filmie Powiększenie (1966) przedstawił unikalny świat w „matrycy aparatu”37, w którym pojęcia ,życie jest grą” i ,świat to teatr” pokazane za pomocą świata klaunów poruszających się pomiędzy „ciałem, piłką i kamerą”38 potwierdzają triadę medium-działaniemechanizm rozgrywanej akcji. Mecz wykreowany przez klaunów pokazuje nie tylko grę w tenisa,

$35 \mathrm{~W}$ oryginalnie napisanym po angielsku tekście Rauschenberga odnośnie do rozgrywanej akcji w dziele Open score: „Double exposure of action”, zob. przyp. 41.

36 Barthes Roland, Roland Barthes, Gdańsk 2011, s. 83-84.

37 George Slover, Blow-Up: Medium, Message, Mythos and Make-Believe, "The Massachusetts Review”, 1968, s. 757.

38 George Slover, Blow-Up: Medium, Message, Mythos and Make-Believe, "The Massachusetts Review”, 1968, s. 761. 
TOM 1, NR 1 (2020)

ale grupę społeczną połączoną jedną wspólną osobliwą realnością - w rzeczywistości jeden świat na ich wyłączność, obserwowany przez zewnętrznego obserwatora (Thomasa), który w końcu zdaje się przyłączać do ich wyimaginowanej gry (podaje on nierzeczywistą piłkę, kiedy klauni udają, że spadła poza boisko - choć piłka pozostaje niewidoczna), jednak na końcu słyszymy dźwięk odbicia piłki. W związku z tym powstaje pytanie, po której stronie stoi Thomas. Thomas podał piłkę klaunom, którzy parodiują rzeczywistość. Co więcej, podał piłkę, która w końcu odbija się w realny sposób, ale nie widzimy już więcej klaunów. W rzeczywistości to pewnego rodzaju zamiana, kładka między dwoma wykreowanymi światami zapisanymi za pomocą kamery na celuloidowej taśmie. Antonioni pokazuje refleksję na temat mediów właściwego mu czasu za pomocą gracza, gry i mechanizmu rozwijanego przed oczyma odbiorcy.

W rzeczywistości to jeden z rzadkich momentów, kiedy role są odwrócone, ukryte i odtworzone, aby pokazać dualizm i iluzję rzeczywistości ${ }^{39}$, ,jak kamera - w rzeczy samej technologia kamery ukazuje nowy wymiar"40.

Robert Rauschenberg w Open Score (1966) proponuje grę w tenisa, w której rakiety są użyte jako pole do transmisji dźwięku uzyskanego przez odbijanie piłki ${ }^{41}$ oraz zmianę oświetlenia pod wpływem uderzeń. Gra toczyła się do czasu zapadnięcia mroku. Ciemność była dla Rauschenberga iluzoryczna (patrz: opis dzieła przez autora, przypis 40). Interaktywna sytuacja, reaktywna, scenicznie multimedialna, była dopełniona przez trzy ekranowe projekcje, na których widzowie

39 „W istocie praca McLuhana bada zmiany naszych paradygmatów postrzeżeniowych w sposób, jakiego nigdzie indziej nie znajdziemy [...]. McLuhan sięga do początków teorii komunikacji, odnajdując je w pracach gramatyków i retoryków, od Cycerona i Kwintyliana po Bacona i Nashe'a [...] w przypadku wszystkich elektrycznych mediów, gdzie «użytkownik» musi się nauczyć wkraczać w proces komunikacji, aby stać się kimś w rodzaju współtwórcy. W elektrycznej rzeczywistości każdy przedmiot jest nie tylko sobą, lecz także reprezentacją złożonego procesu, który wymyka się prostej, logicznej definicji, o czym wie każdy wielbiciel Picassa, Klee czy Mondriana”. Za: M. McLuhan, Wybór tekstów, red. E. McLuhan, F. Zingrone, Poznań 2001, s. 14.

40 George Slover, Blow-Up: Medium, Message, Mythos and Make-Believe, "The Massachusetts Review”, 1968, s. 754.

41 „Rauschenberg note. My theatre piece (today unnamed) begins with an authentic tennis game with rackets wired for transmission of sound. The game's end is the moment the hall is totally dark. The darkness is illusionary. The hall is flooded with infrared (so far invisible to the human eye). A modesty choreographed cast of from 300 to 500 people will enter and be observed and projected by infrared television on large screen for the audience. This is the limit of the realization of the piece for today.

Tennis is movement, put in the context of theatre it is a formal dance improvisation. The unlikely use of the game to control the light and to perform as an orchestra interests me. The conflict of not being able to be an event that is taking place right in front of one except through reproduction is the sort of double exposure of action. A screen of light and a screen of darkness. RR.". Cytat za: Billy Klüver, Open Score by Robert Rauschenberg, 1997 (https://www.artfilms.com.au/item/open-score-by-robert-rauschenberg [dostęp: 05.07.2011]). 
TOM 1, NR 1 (2020)

oglądali sytuację zapisaną kamerami na podczerwień. Jest to jedna z wczesnych prac artystycznych, która jest zaawansowana technologicznie i interaktywna, interakcja jest autorska, sceniczna. Rauschenberg zapisał na końcu notatki do dzieła: „reprodukcja jest rodzajem podwójnej ekspozycji akcji”, podwójnego wystawienia.

Refleksja na temat czasów (Antonioni) przedstawiona jest za pomocą mediów charakterystycznych dla danego okresu (Rauschenberg). [Antonioni] „za Camusem powtarzał, że wybór jest zawsze buntem artysty wobec rzeczywistości" ${ }^{42}$. W obu przypadkach mamy do czynienia $\mathrm{z}$ nowatorskim potraktowaniem gry w tenisa.

Marshall McLuhan pisze: „W przypadku wszystkich elektrycznych mediów [...] użytkownik musi się nauczyć wkraczać w proces komunikacji, aby stać się kimś w rodzaju współtwórcy”43.

Dionisis Kavvathas zwraca uwagę na fakt, iż:

filmowe dzieło Powiększenie Antonioniego ma, między innymi, w swojej zawartości jako formę przekazu (medium) fotografię, która z kolei ma jako przekaźnik granulowaty wszechświat fotograficznej odbitki. Tak więc, kiedy widzimy to dzieło, jego przekaz jest autorefleksyjny: przekaźnik (medium) jako film udostępnia nam możliwość wyświetlania i ujawniania poprzez zbliżenie „treści” niedostępnej dla naszego wzroku. Kiedy zapytano Mallarmégo, czym jest poezja, czyli czym jest jej przekaz, odpowiedział, że jest to kombinacja 24 liter, czyli jej medium. Na pytanie, co to jest kino, Godard odpowiedział: „24 klatki na sekundę”44.

\section{Epilog}

Początkowe doświadczenie odbioru pewnego obrazu, ruchu oddalonych przedmiotów pokierowało mnie w kierunku poszukiwań, gdzie dzieła sztuki pojawiają się jako świadectwa, podania w słowie i obrazie, opowieści, prawdziwe historie wydarzeń, doświadczeń i postaw, a czasem oniryczne bądź fantasmagoryczne formy.

W jednej z prac, tj. w interaktywnej instalacji Moje nieme balony II (2014), użyłam balonów jako metafory iluzorycznego powiększenia (np. kolorowych pikseli). Praca odnosi się do tematu balonu

42 Kino klasyczne, t. 2, red. Tadeusz Lubelski, Iwona Sowińska, Rafał Syska, Kraków 2012, s. 917.

43 Marshall McLuhan, Wybór tekstów, red. Eric McLuhan, Frank Zingrone, Poznań 2001, s. 14.

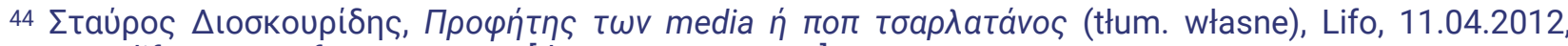
http://www.lifo.gr/mag/features/3164 [dostęp: 11.04.2012]. 
Multidisciplinary Academic Magazine

TOM 1, NR 1 (2020)

w sztuce, znaczenia gry, gracza i mechanizmu rozwijanego przed oczyma odbiorcy i ich znaczenia. Została wyrażona za pomocą interaktywnej instalacji.

Edyta Mąsior, Moje nieme balony II, interaktywna instalacja, kolor, dźwięk, różne wymiary, 2014.

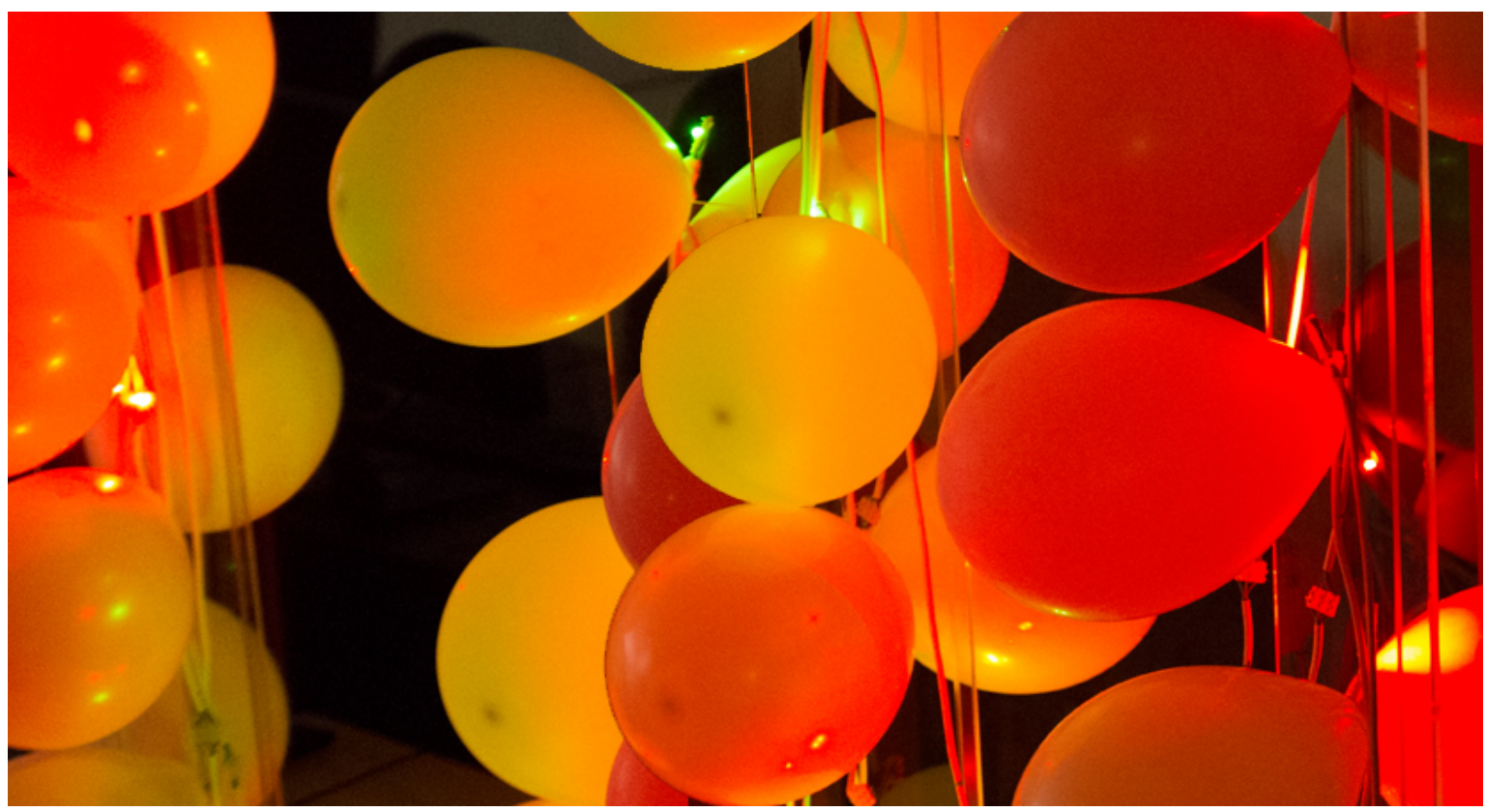

Źródło: archiwum autora

Moje nieme balony II (2014) to interaktywna instalacja, w której dźwięk interreaguje z kolorem za pomocą wielokanałowego sterownika operacyjnego diod LED RGB. Plastyczny, elastyczny przedmiot - balon, rozwinięty i wyposażony w technologiczne podzespoły, staje się dziełem temporalnym, które ulega przeobrażeniom użytkowniczym. Balon to produkt przemysłowy. Jest nie tylko symbolem przejściowego, tymczasowego charakteru rzeczy, ale przede wszystkim symbolem jej utworzenia, a „sposób użycia, jest tym, co nadaje wartości materiałowi” (Giannis Kounellis).

Przez długi czas filmowałam balony w powietrzu, na wietrze, w morzu, na falach, $\mathrm{z}$ grupami ludzi, pomiędzy budynkami, którzy je trzymali, łapali itd., filmowałam, jak spadały w wielkich ilościach, tworząc wielobarwny spektakl, zobaczyłam i zrozumiałam, że ja i wszyscy biorący udział 
TOM 1, NR 1 (2020)

w tych działaniach zajmujemy się formą tymczasowego obiektu. Przedmiotu, który daje wrażenie, że ja i przedmiot znajdujemy się w granicach nieistnienia i w granicach istnienia. Delikatna dualna forma, prawie niematerialna obecność balonów dawała ledwo ujmowalne wrażenie działania osób z nimi związanych. Sam przedmiot łatwo traci wszelkie swoje właściwości. Jest to podstawowa obserwacja, która na końcu tej analizy badawczej doprowadziła mnie do jej początkowego momentu.

Noblista Thomas Stearns Eliot finalny moment poszukiwania ujął w słowa, które oddają stan tej pracy: koniec całego poszukiwania prowadzi nas do miejsca, z którego rozpoczęło się jedno miejsce, które znaliśmy od samego początku.

To, co zwiemy początkiem, to często jest kresem,

A dojście do kresu oznacza początek ${ }^{45}$.

45 Eliot T.S., Little Gidding, nr 4: Cztery kwartety, cz. 5, 1943. 


\section{BIBLIOGRAFIA}

Barthes Roland, Roland Barthes, Gdańsk 2011.

Baumgarten Alexander, Metaphysics: A Critical Translation with Kant's Elucidations, trans. and ed. Courtney D. Fugate, John Hymers, London-New Delhi-New York-Sydney 2013.

Cortázar Julio, Las armas secretas y otros relatos, Madrid 1964.

Cortázar Julio, Opowiadania 1, Warszawa 2009.

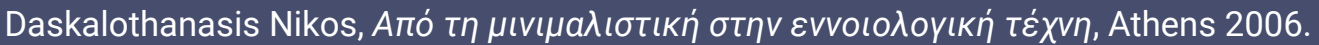

Derrida Jacques, O gramatologii, tłum. Bogdan Banasiak, Warszawa 1998.

Eliot Thomas Stearns, Little Gidding, nr 4: Czwarty kwartet, cz. 5, 1943.

Faggin Giorgio, Vocabolario Della Lingua Friulana, Udine 1985.

Ferrua Pietro, Blow-up from Cortázar to Antonioni, „Literature/Film Quarterly”, vol. 4, 1976, No. 1.

Heller Michał, Elementy filozofii przyrody, Kraków 2014.

Kino klasyczne, t. 2, red. Tadeusz Lubelski, Iwona Sowińska, Rafał Syska, Kraków 2012.

Klüver Billy, Open Score by Robert Rauschenberg, 1997. https://www.artfilms.com.au/item/open-score-byrobert-rauschenberg.

Krzysztof Kościuszko, Pojęcie - idea - problem w „Różnicy i powtórzeniu” G. Deleuze’a, „Humanistyka i Przyrodoznawstwo", 2004, nr 10.

Marzec Andrzej, Différance Derridy. Czy błąd daje się (wy)tłumaczyć?, „Przekładaniec. A Journal of Translation Studies", 2011, nr 24.

Maturana Humberto, Reflections on My Collaroration with Francisco Varela, Biology of Cognition, Constructivist Foundations, vol. 7, 2012, No. 3.

Mąsior Edyta, Wizualny palimpsest na temat balonu. Wideo Moje nie-me balony. Balon, żyłka i trzy osoby z serii Balony, „Annales Universitatis Paedagogicae Cracoviensis. Studia de Arte et Educatione”, 2013, vol. 8.

McLuhan Marshall, Understanding Media: The extensions of man, London-New York 1994.

McLuhan Marshall, Wybór tekstów, red. Eric McLuhan, Frank Zingrone, Poznań 2001.

Michnik Antoni, Gem, set, algorytm. Intermedialne projekty wykorzystujące dane tenisowe, „Kultura Współczesna", 2017, nr 1. 
Miczka Tadeusz, W Cinecittà i okolicach. Historia kina włoskiego od połowy lat pięćdziesiątych do końca lat osiemdziesiątych XX wieku, Kraków 1993.

Navridis, La Biennale di Venezie, 49., 2001.

Nietzsche Friedrich, Pisma pozostałe 1862-1875, Kraków 1993.

Nikos Navridis, Ateny 2003.

Paucar-Caceres Alberto, Harnden Roger, Commentary on the Separate Prologues by Humberto Maturana and Francisco Varela to the Second Edition of 'De Máquinas y Seres Vivos-Autopoiesis: La organización de lo vivo'Twenty Years After, „Systems Research and Behavioral Science Syst. Res.”, 2011, No. 28.

Peavler Terry J., Blow-Up: A Reconsideration of Antonioni's Infidelity to Cortázar, „Modern Language Association, PMLA", 1979, vol. 94, No. 5.

Sacks Olivier, Rzeka świadomości, Poznań 2018.

Segal Lynn, The Dream of the Reality, Heinz von Foerster's Constructivism, New York 2001.

Slover George, Blow-Up: Medium, Message, Mythos and Make-Believe, „The Massachusetts Review”, 1968.

Straeubig Michael, On the distinction between distinction and division, „Technoetic Arts: A Journal of Speculative Research", vol. 13, 2015, No. 3.

Tinazzi Giorgo, Michelangelo Antonioni, Firenze 1985.

Wendorf Richard, Antonioni's "Blow-up": Implicated Artists and Unintentional Art, „The Journal of Aesthetic Education", vol. 16, 1982, No. 1.

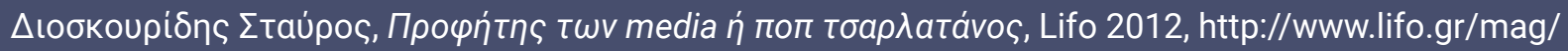
features/3164. 